\title{
POLÍTICAS PARA A EDUCAÇÃo PROFISSIONAL E TECNOLÓGICA NO BRASIL
} (2003-2017)

\author{
POLÍTICAS PARA LA EDUCACIÓN PROFESIONAL Y TECNOLÓGICA EN BRASIL \\ (2003-2017)
}

POLICIES FOR PROFESSIONAL AND TECHNOLOGICAL EDUCATION IN BRAZIL (2003-2017)

\author{
Fábio Mamoré CONDE ${ }^{1}$ \\ Regina Tereza Cestari de OLIVEIRA ${ }^{2}$
}

RESUMO: O artigo apresenta resultados de pesquisa e tem como objetivo discutir a proposição, assim como o processo da materialização de políticas para a educação profissional e tecnológica, no período de 2003 a 2017, ressaltando as concepções em disputa na área, no campo das contradições. A investigação se apoia em fontes documentais e em dados de relatórios oficiais disponibilizados nesse período. Mostra que a instituição da Rede Federal de Educação Profissional, Científica e Tecnológica, abarcando os Institutos Federais de Educação, Ciência e Tecnologia, possibilita a ampliação de vagas, do número de inscritos para ingresso e de matriculados nas Instituições da Rede Federal. Apresenta, ainda, a alocação crescente de recursos públicos, movimento que se interrompe a partir de 2015, com diminuição acentuada nos anos de 2016 e 2017.

PALAVRAS-CHAVE: Política educacional. Educação profissional e tecnológica. Rede Federal de Educação Profissional, Científica e Tecnológica. Recursos públicos.

RESUMEN: El artículo presenta resultados de investigación y tiene como objetivo discutir la proposición, así como el proceso de la materialización de políticas para la educación profesional y tecnológica, en el período de 2003 a 2017, resaltando las concepciones en disputa en el área, en el campo de las contradicciones. La investigación se apoya en fuentes documentales y en datos de informes oficiales, disponibles en ese período. Muestra que la institución de la Red Federal de Educación Profesional, Científica y Tecnológica, abarcando los Institutos Federales de Educación, Ciencia y Tecnología, posibilita la ampliación de vacantes, del número de inscritos para ingreso y de matriculados en las Instituciones de la Red Federal. Se presenta, además, la asignación creciente de recursos públicos, movimiento que se interrumpe a partir de 2015, con disminución acentuada en los años 2016 y 2017.

${ }^{1}$ Instituto Federal de Educação, Ciência e Tecnologia de Rondônia (IFRO), Porto Velho - RO - Brasil. Universidade Católica Dom Bosco (UCDB), Campo Grande - MS-Brasil. Analista de Tecnologia de Informação. Diretoria de Tecnologia da Informação. Doutorando em Educação da Universidade Católica Dom Bosco. ORCID: https://orcid.org/0000-0002-6145-9777. E-mail: fabio.conde@ifro.edu.br.

${ }^{2}$ Universidade Católica Dom Bosco (UCDB), Campo Grande - MS - Brasil. Docente do Programa de PósGraduação em Educação - Mestrado e Doutorado. ORCID: https://orcid.org/0000-0001-5500-7478. E-mail: reginacestari@ucdb.br

RIAEE - Revista Ibero-Americana de Estudos em Educação Araraquara, v. 14, n. esp. 3, p. 1797-1812, out., 2019. E-ISSN: 1982-5587. 
PALABRAS CLAVE: Política educativa. Educación profesional y tecnológica. Red Federal de Educación Profesional, Científica y Tecnológica. Recursos públicos.

ABSTRACT: The article presents research results and aims to discuss the proposal, as well as the process of the materialization of policies for professional and technological education, from 2003 to 2017, highlighting the concepts in dispute in the area, in the field of contradictions. The research relies on documentary sources and official reporting data made available during this period. It shows that the institution of the Federal Network of Professional, Scientific and Technological Education, encompassing the Federal Institutes of Education, Science and Technology, allows the expansion of vacancies, the number of enrolled students and those enrolled in Federal Network Institutions. It also presents the increasing allocation of public resources, a movement that is interrupted after 2015, with a marked decrease in the years 2016 and 2017.

KEYWORDS: Educational policy. Professional and technological education. Federal Network of Vocational, Scientific and Technological Education. Public resources.

\section{Introdução}

Este artigo apresenta resultados de pesquisa e tem como objetivo discutir o contexto da proposição e o processo da materialização de políticas para a educação profissional e tecnológica, a partir de 2003, abrangendo o governo de Luiz Inácio Lula da Silva (2003-2010), do Partido dos Trabalhadores (PT), os governos subsequentes, de Dilma Vana Rousseff (20112016) ${ }^{3}$, também do PT, e de Michel Temer (2016-2018), do Movimento Democrático Brasileiro (MDB).

Justifica-se o recorte temporal na medida em que a posse do governo Lula da Silva, em 2003, demarca o início de uma nova conjuntura, entendendo-se que, “[...] não é o tempo cronológico que define uma conjuntura, mas a natureza dos acontecimentos e dos fatos, e as forças sociais que os produzem”. Assim, como conjuntura a década começa em janeiro de 2003 (FRIGOTTO, 2011, p. 237). A análise vai até 2017, levando-se em consideração a disponibilidade dos dados até este ano.

Para tanto, o texto se apoia na análise documental, tendo como fontes as orientações e diretrizes oriundas dos governos federais, assim como os dados retirados de relatórios oficiais provenientes do plano de expansão da Rede Federal de Educação Profissional e Tecnológica (Rede Federal de EPCT), dos relatórios anuais de análise dos indicadores de gestão da Rede Federal, dos relatórios de gestão anual da Secretaria de Educação Profissional e Tecnológica

\footnotetext{
${ }^{3}$ A presidente foi afastada em 12 de maio de 2016, em consequência de um processo de impeachment.
} 
(SETEC) e dos relatórios do Instituto Federal de Educação, Ciência e Tecnologia de Rondônia (IFRO).

Parte-se do pressuposto de que a formulação de políticas educacionais no âmbito do Estado resulta das opções da correlação de forças e de concepções em disputa, entendendo-se que o Estado compreende, além da sociedade política (aparelho governamental), a sociedade civil (GRAMSCI, 1976), ou seja, em uma concepção ampla, utilizando os termos de Dourado (2010),

[...] seus embates e os percursos históricos em que estas se constroem, tendo por marco as condições objetivas em que se efetivam a relação educação e sociedade, os processos sistemáticos ou não de gestão, bem como o papel das instituições educativas e dos diferentes atores que constroem o seu cotidiano (DOURADO, 2010, 678).

Entende-se, também, que o cenário da proposição de políticas não é o mesmo da materialização ou "Estado em ação", e que o processo de materialização é permeado por "múltiplas variáveis intervenientes e nem sempre coincidentes, ainda que ratifiquem, por vezes, as concepções em disputa" (DOURADO, 2017, p. 42).

Diante dessas considerações, o texto está organizado em duas seções: a primeira trata do contexto da proposição da política de educação profissional e tecnológica e do processo da materialização da política que instituiu a Rede Federal de Educação Profissional, Científica e Tecnológica e criou os Institutos Federais de Educação Profissional e Tecnológica (IFETS), ressaltando alguns pressupostos que marcam a proposta de educação profissional e tecnológica; a segunda, analisa os recursos públicos, com foco nos gastos da Rede Federal. Essa escolha não é arbitrária, pois entende-se que o financiamento público é condição objetiva para a materialização da política pública.

\section{Configuração da Rede de Educação Profissional e Tecnológica}

A partir de 2003, no governo de Luiz Inácio Lula da Silva (2003-2010), a educação profissional e tecnológica se apresenta como alternativa para a educação superior, em uma proposta caracterizada pela expectativa de mudança quanto aos princípios e concepções de formação e a possibilidade de debate sobre a proposição de políticas, de modo particular, para a educação profissional e tecnológica.

Para tanto, o Ministério da Educação (MEC) organizou o Seminário intitulado "Educação Profissional 'Concepções. Experiências. Problemas e Propostas"”. Os Anais deste 
Seminário ressaltam que, na década anterior, as autoridades governamentais concordaram com os princípios dos organismos internacionais (Banco Mundial - BIRD e Banco Interamericano de Desenvolvimento - BID) para as reformas educacionais, com orientações pautadas em uma linha economicista (BRASIL, 2003). Desse modo,

[...] a redefinição das atribuições do Estado e a revisão dos parâmetros e prioridades da despesa pública se fizeram necessárias, orientando a diversificação da oferta educativa com a preocupação de obter maior eficiência no gasto social (BRASIL, 2003, p. 24).

Afirmam, ainda, que está presente nas escolas de Educação Profissional (EP) a concepção de qualidade procedente da indústria. Enfatizam que: "Por muito tempo foi o setor produtivo que indicou o que é qualidade para a EP. Qualidade para a empresa é produzir conforme a necessidade do cliente ou qualidade é adequação ao uso do produto. O aluno é tratado como cliente" (BRASIL, 2003, p. 44).

E pontuam a necessidade de romper com essa visão de qualidade e incorporar uma visão mais humanista. Segundo essa perspectiva,

[...] no lugar do mercado de trabalho, pensar no mundo do trabalho e ser crítico ao modelo tecnicista. Na EP [educação profissional], é preciso dar o salto do modelo da qualidade total empresarial para o modelo da qualidade social, comprometer-se com a realidade do país. E a sociedade que tem de indicar os parâmetros de qualidade, para isso ela precisa ser ouvida. (BRASIL, 2003, p. 44).

Nesse sentido, o documento denominado "Proposta em discussão: Políticas Públicas para a Educação Profissional e Tecnológica”, ressalta a importância de recuperar o papel fundamental do ensino médio, qual seja,

[...] estabelecer a relação entre o conhecimento e a prática de trabalho. Tratase de explicitar como o conhecimento (objeto específico do processo de ensino), isto é, como a ciência se converte em potência material no processo de produção. Tal explicitação deve envolver o domínio não apenas teórico, mas também prático sobre o modo como o saber se articula com o processo produtivo (BRASIL, 2004, p. 13). 
Ressalta que a organização da educação profissional e tecnológica vinculada ao ensino médio "deve propiciar aos alunos o domínio dos fundamentos científicos das técnicas diversificadas e utilizadas na produção, e não o simples adestramento em técnicas produtivas" (BRASIL, 2004, p. 13).

O documento expressa a dualidade educacional histórica. Essa dualidade atribui à escola duas tarefas contraditórias: formar o cidadão, aquele que ampliará sua participação cultural, política e econômica, enquanto produtor e consumidor; e formar o trabalhador, aquele cujas tarefas estão em crescente simplificação, em postos de trabalho que permitem reduzida mobilização de suas energias mentais, tais como reflexão e criatividade, como esclarece Kuenzer (1997).

É no âmbito dessa discussão que o governo Lula da Silva lançou, em 2005, o Plano de Expansão da Rede Federal de Educação Tecnológica. Este Plano afirma que:

Esta proposta está embasada numa concepção de mundo, de nação, de homem e de trabalho onde o ser humano é o parâmetro primeiro e principal, cujos processos produtivos e relações sociais devem eticamente reafirmar e respeitar (BRASIL, 2005, p. 3).

Segundo esse entendimento, conforme Ciavatta (2007), retornou a expectativa da articulação entre formação geral, as ciências e as humanidades, com a formação específica, profissional, técnica e tecnológica.

O Plano de Expansão define como objetivo ampliar a área de atuação da rede federal de educação profissional e tecnológica para formar cidadãos críticos e profissionais competentes a partir da compreensão da relação do mundo do trabalho, da cultura e das ciências. Reconhece a importância de que regiões mais distantes dos grandes centros formadores tenham um modelo de instituição pública, gratuita, de qualidade e acessível, comprometida com a inclusão social dos contingentes "menos favorecidos da população" (BRASIL, 2005, p. 6), e destaca a intenção de oferecer uma rede de formação profissional com a melhor cobertura geográfica possível e diálogo com os arranjos produtivos locais (BRASIL, 2005).

Nota-se, na proposta, o interesse em utilizar a educação profissional e tecnológica como instrumento mediador para atender demandas de diferentes grupos sociais, por meio de cursos não aligeirados, porém, além da formação técnica, apresenta a possibilidade de acesso e conclusão da educação superior, como parte de sua implantação e a vinculação com os arranjos produtivos locais.

Na justificativa de expansão, o documento propõe, por exemplo, para os Estados do Acre, Mato Grosso do Sul e Rondônia, escolas técnicas específicas, face à “[...] contundente 
carência de oportunidades de educação profissional, tanto em cursos técnicos de nível médio, como nos de formação inicial e continuada de trabalhadores e arranjos produtivos locais" (BRASIL, 2005, p. 9), sendo para o Acre, proposta pedagógica nas áreas de Agropecuária, Indústria e Meio-Ambiente; para Mato Grosso do Sul, nas áreas de Agropecuária, Agroindústria, Indústria, prestando suporte ainda na área de turismo e requerendo aporte de recursos financeiros e humanos similares aos projetados para o Acre; para Rondônia, nas áreas de Agropecuária, Agroindústria, Meio-Ambiente e Informática. A partir do objetivo de ampliar a oferta de educação profissional e tecnológica, o plano relaciona essa educação com a expectativa de diminuição de desigualdades sociais e combate ao desemprego e exclusão social (BRASIL, 2005).

No ano de 2005, as instituições federais de EPT constituíam-se de escolas agrotécnicas, Centros Federais de Educação Tecnológica (CEFETs), e escolas técnicas vinculadas, e formavam uma rede de 140 unidades (BRASIL, 2011a).

Em decorrência do Plano de Expansão é que se instituiu a Rede Federal de Educação Profissional, Científica e Tecnológica (Rede Federal) e foram criados os Institutos Federais de Educação Profissional e Tecnológica, mediante a Lei ${ }^{\circ}$. 11.892, de 29 de dezembro de 2008, com as seguintes instituições, conforme o Art. $1^{\circ}$ : Institutos Federais de Educação, Ciência e Tecnologia - Institutos Federais; Universidade Tecnológica Federal do Paraná (UTFPR); Centros Federais de Educação Tecnológica Celso Suckow da Fonseca - CEFET-RJ e de Minas Gerais (CEFET-MG) (BRASIL, 2008).

Portanto, em 2008 a Rede Federal alcançou todos os estados brasileiros e o Distrito Federal, constituída por 38 Institutos Federais (oito Escolas Técnicas Vinculadas às Universidades Federais se tornaram campus de Institutos Federais), a Universidade Tecnológica Federal do Paraná, 24 Escolas Técnicas Vinculadas às Universidades Federais e dois Centros Federais de Educação Tecnológica (BRASIL, 2008). No ano de 2012, por meio da Lei $n^{\circ}$. 12.677, a composição da Rede Federal foi ampliada, com a alteração do Art. $1^{\circ}$ da lei de criação, que acrescentou o Colégio Pedro II (BRASIL, 2012c).

A instituição da Rede Federal ampliou, em decorrência, o quantitativo de vagas ofertadas, da quantidade de inscritos nos processos de seleção de ingresso e, portanto, do número de alunos matriculados, como se pode verificar na tabela a seguir. 
Tabela 1 - Número de vagas, de inscritos nos processos seletivos e de matriculados na Rede Federal

\begin{tabular}{c|c|c|c|c}
\hline Ano & Vagas & $\begin{array}{c}\text { Inscritos nos } \\
\text { processos seletivos }\end{array}$ & Vagas/Inscritos & Matriculados \\
\hline 2009 & s/d & s/d & 3,90 & s/d \\
\hline 2010 & 194.624 & 1.122 .645 & 5,77 & s/d \\
\hline 2011 & 186.623 & 1.083 .885 & 5,81 & 738.673 \\
\hline 2012 & 256.987 & 1.289 .110 & 5,02 & 804.043 \\
\hline 2013 & 264.438 & 1.327 .303 & 5,02 & 678.436 \\
\hline 2014 & 217.996 & 1.374 .809 & 6,31 & 772.277 \\
\hline 2015 & 236.472 & 1.295 .205 & 5,48 & 874.171 \\
\hline 2016 & 291.236 & 1.656 .751 & 5,69 & 1.004 .737 \\
\hline 2017 & 474.160 & 1.902 .016 & 4,01 & . \\
\hline
\end{tabular}

Fonte: Brasil (2011a, 2012a, 2013a, 2014a, 2015, 2016, 2017, 2018). Adaptado pelos autores.

Observa-se que nos anos de 2011 e 2014 houve redução no quantitativo de vagas ofertadas pela Rede Federal, com ampliação de 38\% em 2012 e de 23\% no ano de 2016. A maior ampliação, de 63\%, ocorreu no ano de 2017. Entre 2010 e 2017 ampliou-se, aproximadamente, 2,43 vezes o número de vagas ofertadas. A redução na oferta de vagas em 2014 é justificada no relatório desse ano da seguinte forma,

É importante salientar que a redução do número de vagas não ocorreu nos cursos regulares (presenciais e a distância), mas foi uma decorrência da retirada das vagas de e-Tec ${ }^{4}$ que em 2014 puderam ser separadas a partir de uma nova funcionalidade no SISTEC, algo próximo a 50 mil vagas. De fato, houve um pequeno aumento em torno de 5 mil vagas nos cursos regulares da Rede Federal (BRASIL, 2015, p. 23).

No que se refere aos inscritos nos processos seletivos há, em média, ampliação de $4 \%$ ao ano. Com exceção dos anos de 2011 e 2015, que registraram decréscimo, os demais anos apresentam acréscimo, com maior variação nos anos de 2012 e 2016. Quanto à relação candidatos/vagas, com exceção de 2009 não se observa diferença significativa na variabilidade dos dados. O relatório de 2012 destaca que, apesar da redução na relação candidatos/vagas, há um aumento significativo do quantitativo de vagas ofertadas e do interesse "de cidadãos nos cursos de formação e qualificação junto à Rede Federal” (BRASIL, 2013a, p. 36).

No que se refere às matrículas ${ }^{5}$, observa-se o aumento do número de matriculados, com média anual de 14\%, com decréscimo em 2014 causado pela retirada dos alunos da Rede e-Tec. Nota-se, porém, que este ano foi o que registrou a maior procura pelos cursos da Rede Federal, com a relação de candidatos/vagas de 6,31.

${ }^{4}$ Conforme o Decreto $\mathrm{n}^{\text {o. }}$ 7.589, de 26 de outubro de 2011, a Rede e-Tec Brasil tem a finalidade de desenvolver a educação profissional e tecnológica na modalidade de educação a distância, ampliando e democratizando a oferta e o acesso à educação profissional pública e gratuita no País (BRASIL, 2011b).

${ }^{5}$ Os relatórios não apresentam o quantitativo absoluto de dados nos anos de 2009 e 2010. 
No entanto, como analisa Frigotto (2011), embora a educação profissional, técnica e tecnológica tenha se constituído na grande prioridade do período de 2003 a 2010, não alterou seu caráter dominantemente privado. Enfatiza que a opção pela parceria do público com o privado não favorece a reversão da dualidade educacional.

A transformação da Rede de Escolas Técnicas Federais em Centros Federais de Educação Tecnológica (CEFTS), nesse período, em universidades tecnológicas ou Institutos federais de Ciência e Tecnologia (IFETS) não ajuda, portanto, “[...] a reverter o caráter dominantemente privado e a apropriação privada de recursos públicos na área" (FRIGOTTO, 2011, p. 246).

No governo seguinte, de Dima Rousseff (2011-2014), a apropriação privada de recursos públicos pode ser observada nos Relatórios de Gestão da SETEC/MEC. Em 2011 foi instituído o Programa Nacional de Acesso ao Ensino Técnico e Emprego (Pronatec) e a oferta de bolsaformação. No ano de 2013, pela bolsa-formação, "foi repassado para as instituições privadas o montante de $\mathrm{R} \$ 51.951 .486,10 ”$ (BRASIL, 2014b, p. 26). Outra forma de apropriação dos recursos públicos é o Financiamento Estudantil para a educação profissional e tecnológica (FIES Técnico), como ação pertencente ao Pronatec, que possibilita o financiamento para estudantes e empresas (BRASIL, 2012b, 2013b), em cursos que "são ofertados pelas escolas técnicas de nível médio privadas, e pelos serviços nacionais de aprendizagem" (BRASIL, 2013b, p. 15).

\section{Recursos Públicos para a Rede Federal}

No plano financeiro, os gastos com investimento ${ }^{6}$, apresentados na Tabela 2, demonstram que, em relação ao valor nominal, houve aumento entre os anos de 2011 e 2014, e que a partir do ano de 2015 teve início a redução dos valores gastos com investimento. $\mathrm{Na}$ relação gasto total e gasto com investimento, nota-se o menor percentual de investimento nos dois últimos anos, 2016 e 2017, com o extremo de 3,10\% no ano de 2017. O valor gasto com investimento neste último representa uma redução, em relação ao ano anterior, de $-40,36 \%$ em valor nominal e -44,10\% no valor ajustado; na comparação entre os anos de 2011 e 2017,

${ }^{6}$ Os valores nominais (valor registrado no ano, sem atualização da inflação) do gasto total e investimento estão disponíveis nos relatórios anuais de 2011 a 2017. Esses valores foram atualizados para janeiro de 2017, com base no cálculo do Índice Nacional de Preços ao Consumidor Amplo - IPCA do Instituto Brasileiro de Geografia e Estatística - IBGE, variação adotada na Emenda Constitucional no 95, de 15 de dezembro de 2016 para o Novo Regime Fiscal, proveniente da PEC 241/2016; cálculo realizado na 'Calculadora do Cidadão' do Banco Central do Brasil (BANCO CENTRAL DO BRASIL, 2019). 
observa-se redução de $-66,64 \%$ em valores ajustados. Considerando os anos de 2012 e 2017, observa-se o aumento de $66,71 \%$ do quantitativo de alunos matriculados e uma diminuição de $-66,26 \%$ do gasto do investimento.

Tabela 2 - Gastos com investimento em relação ao gasto total na Rede Federal

\begin{tabular}{l|l|l|l|l}
\hline Ano & $\begin{array}{c}\text { Gasto com } \\
\text { Investimento (nominal) }\end{array}$ & $\begin{array}{c}\text { Gasto com } \\
\text { Investimento } \\
\text { (ajustado para 2017) }\end{array}$ & $\begin{array}{c}\text { Percentual do } \\
\text { gasto total }\end{array}$ & $\begin{array}{c}\text { Variação em relação } \\
\text { ao ano anterior } \\
\text { (nominal | ajustado) }\end{array}$ \\
\hline 2009 & $\mathrm{~s} / \mathrm{d}$ & $\mathrm{s} / \mathrm{d}$ & $6,4 \%$ & $\mathrm{~s} / \mathrm{d}$ \\
\hline 2010 & $\mathrm{~s} / \mathrm{d}$ & $\mathrm{s} / \mathrm{d}$ & $23,2 \%$ & $\mathrm{~s} / \mathrm{d}$ \\
\hline 2011 & $\mathrm{R} \$ 947.517 .733,42$ & $\mathrm{R} \$ 1.421 .287 .401,83$ & $16,6 \%$ & $\mathrm{~s} / \mathrm{d}$ \\
\hline 2012 & $\mathrm{R} \$ 997.695 .652,48$ & $\mathrm{R} \$ 1.405 .174 .810,17$ & $14,98 \%$ & $5,30 \% \mid-1,13 \%$ \\
\hline 2013 & $\mathrm{R} \$ 1.246 .045 .948,00$ & $\mathrm{R} \$ 1.658 .144 .494,15$ & $15,03 \%$ & $24,89 \% \mid 18,00 \%$ \\
\hline 2014 & $\mathrm{R} \$ 1.367 .470 .230,00$ & $\mathrm{R} \$ 1.718 .169 .046,99$ & $13,69 \%$ & $9,74 \% \mid 3,62 \%$ \\
\hline 2015 & $\mathrm{R} \$ 1.040 .934 .211,00$ & $\mathrm{R} \$ 1.229 .132 .097,64$ & $9,01 \%$ & $-23,88 \% \mid-28,46 \%$ \\
\hline 2016 & $\mathrm{R} \$ 795.016 .479,00$ & $\mathrm{R} \$ 848.218 .584,27$ & $5,76 \%$ & $-23,62 \% \mid-30,99 \%$ \\
\hline 2017 & $\mathrm{R} \$ 474.116 .364,00$ & $\mathrm{R} \$ 474.116 .364,00$ & $3,10 \%$ & $-40,36 \% \mid-44,10 \%$ \\
\hline
\end{tabular}

Fonte: Brasil (2011a, 2012a, 2013a, 2014a, 2015, 2016, 2017, 2018). Adaptado pelos autores.

O percentual de gasto com investimento em relação ao total, em 2017, pode ser considerado "extremado", conforme termo utilizado pela SETEC/MEC, registrado no relatório de 2008, ou seja, significa que "os gastos com investimentos representam menos de $5 \%$ dos gastos totais" (BRASIL, 2009, p. 57). O relatório ressalta que, no período anterior a 2008, quer dizer,

[...] nos últimos quinze anos houve uma acentuada redução nos recursos destinados à realização de investimentos no âmbito das Instituições Federais de Educação Tecnológica de modo geral, e com mais rigor no caso particular das Escolas Agrotécnicas Federais (BRASIL, 2009, p. 57).

Infere-se que a redução no percentual de investimento, em relação ao gasto total nos anos de 2016 e 2017, representa um retorno ao período anterior à criação dos Institutos Federais. Para contextualizar o movimento de diminuição nos valores destinados para investimento, observa-se que "em 2015, o percentual caiu ainda mais, chegando a 9\%, reflexo principalmente do corte de 47\% de capital" (BRASIL, 2016, p. 28).

O relatório de 2016 assinala um segundo motivo para a redução dos investimentos no ano, ou seja, 
A tendência de conclusão das obras e ações de infraestrutura relativas à expansão da Rede Federal pode ser constatada por meio do medidor 'Gastos com Investimentos'. Em 2016 esse índice atingiu o menor valor, 5,76\%, quase três vezes menor do que o maior valor do período que foi $15,03 \%$ em 2013 (BRASIL, 2017, p. 46).

Nessa direção, o relatório de 2017, ao analisar a redução do investimento, reforça as justificativas apresentadas nos anos de 2015 e 2016 ao afirmar que,

Esta realidade se explica por dois fatores: primeiro, obviamente, ligada ao esforço governamental pela redução dos gastos públicos, seguido de contingenciamento orçamentários, fundamentais para o reequilíbrio financeiro do país; depois, pela chegada ao estágio de consolidação da expansão física da Rede Federal. (BRASIL, 2018, p. 35).

Chama-se a atenção, nos relatórios de 2015 e 2017, para a alteração na justificativa apresentada sobre a redução dos valores gastos em investimento. O relatório de 2015 afirma que a redução é "reflexo principalmente do corte de 47\% de capital" (BRASIL, 2016), enquanto o relatório de 2017 se refere ao "esforço governamental pela redução dos gastos públicos" (BRASIL, 2018). A alteração da expressão de 'corte' para 'esforço governamental' sinaliza mudanças na concepção e nas medidas para as políticas públicas educacionais, encaminhadas pelo Governo Temer (2016-2018), ao justificar sobre a redução dos valores destinados à Rede Federal.

Observa-se na Tabela 3 aumento anual do gasto total no período. Em valor nominal, a maior elevação se dá no ano de 2013 e a menor no ano de 2017. Ao se considerar a variação do gasto em relação ao ano anterior, verifica-se, a partir de 2014, redução no valor do indicador. O menor percentual de acréscimo ocorreu em 2017, com $11 \%$ em valor nominal e 3,8\% em valor ajustado.

Tabela 3 - Valores totais gastos no período de 2011 a 2017 na Rede Federal

\begin{tabular}{|c|c|c|c|}
\hline Ano & $\begin{array}{l}\text { Gastos totais } \\
\text { (nominal) }\end{array}$ & $\begin{array}{c}\text { Gastos totais } \\
\text { (ajustado para 2017) }\end{array}$ & $\begin{array}{c}\text { Variação em relação ao ano } \\
\text { anterior } \\
\text { (nominal } \mid \text { ajustado) }\end{array}$ \\
\hline 2011 & $\mathrm{R} \$ 5.712 .301 .727,68$ & $\mathrm{R} \$$ 8.568.517.711,76 & Base \\
\hline 2012 & $\mathrm{R} \$ 6.660 .862 .404,21$ & $\mathrm{R} \$ 9.381 .293 .825,60$ & \begin{tabular}{l|l|}
$17 \%$ & $9,5 \%$ \\
\end{tabular} \\
\hline 2013 & $\mathrm{R} \$ 8.291 .532 .661,00$ & $\mathrm{R} \$ 11.033 .749 .800,31$ & $24 \% \mid 17,6 \%$ \\
\hline 2014 & $\mathrm{R} \$ 9.987 .279 .216,00$ & $\mathrm{R} \$ 12.548 .597 .867,90$ & $20 \% \mid 13,7 \%$ \\
\hline 2015 & $\mathrm{R} \$ 11.556 .063 .644,00$ & $\mathrm{R} \$ 13.645 .366 .438,25$ & \begin{tabular}{l|l|}
$16 \%$ & $8,7 \%$ \\
\end{tabular} \\
\hline 2016 & $\mathrm{R} \$ 13.811 .902 .195,00$ & $\mathrm{R} \$ 14.736 .187 .783,94$ & $20 \% \mid 8 \%$ \\
\hline 2017 & $\mathrm{R} \$ 15.300 .257 .666,00$ & $\mathrm{R} \$ 15.300 .257 .666,00$ & \begin{tabular}{l|l|}
$11 \%$ & $3,8 \%$ \\
\end{tabular} \\
\hline
\end{tabular}

Fonte: Brasil (2011a, 2012a, 2013a, 2014a, 2015, 2016, 2017, 2018). Adaptado pelos autores. 
A elevação dos gastos totais não permite perceber, inicialmente, o contingenciamento iniciado em 2015 pelo governo federal. No entanto, exemplifica-se com os dados do Relatório de Gestão dos anos de 2015 e 2016 do IFRO. O relatório de 2015 afirma que "Como fator interveniente no exercício de 2015, cabe destacar o grande contingenciamento (corte) orçamentário promovido pelo Governo Federal". (IFRO, 2016, p. 108). Acrescenta que o corte no investimento em 2015 comprometeu “o planejamento de consolidação e expansão do IFRO principalmente no tocante às questões de infraestrutura" (IFRO, 2016, p. 82).

Nesse sentido, parece que, mesmo com o aumento dos gastos totais, estes não foram suficientes para a efetivação das ações institucionais programadas pelo Instituto. Situação recorrente em 2016, na medida em que, conforme o relatório,

[...] as principais dificuldades enfrentadas relacionam-se ao contingenciamento orçamentário demandando a supressão de alguns contratos, podendo impactar no serviço prestado devido à mudança da dinâmica das atividades (IFRO, 2017, p. 157).

Como se verifica, apesar da ampliação no número de vagas e de alunos matriculados nas instituições que compõem a Rede Federal, observa-se diminuição dos recursos públicos quanto ao percentual de investimento em relação ao gasto total, devido aos cortes mencionados, acentuadamente em 2016 e 2017. Esses anos correspondem ao período de instabilidade política, em decorrência do afastamento da presidente Dilma Rousseff, em maio de 2016, resultado um Golpe que foi sendo constituído pela "via da erosão da governabilidade promovido no arranjo jurídico-midiático-parlamentar" (DOURADO, 2018) e, por consequência, de mudanças nas medidas encaminhadas pelo Governo Temer (2016-2018), especialmente na configuração de politicas públicas educacionais.

\section{Considerações finais}

A conjuntura histórica, a partir de 2003, correspondente ao governo de Lula da Silva (2003-2010), possibilitou a inserção da sociedade civil na agenda governamental do debate na formulação de políticas públicas, especialmente para a educação profissional e tecnológica.

Conforme os dados apresentados, o objetivo de ampliar a área de atuação da educação profissional e tecnológica por meio do Plano de Expansão da Rede Federal de Educação Profissional e Tecnológica, publicado em 2005, nesse governo, foi precedido de seminários mediados pelo MEC. As publicações, resultantes desses seminários, retratam as disputas de concepção em torno da educação profissional e tecnológica e a indicação de uma proposta, com 
base em uma concepção humanista, assentada na qualidade social, como categoria orientadora das políticas de educação profissional e tecnológica, que busca romper com a concepção funcionalista, estreita e restrita, voltada à formação com base nos interesses do mercado.

No processo da materialização da política de educação profissional e tecnológica, a instituição da Rede Federal de Educação Profissional, Científica e Tecnológica e a expansão das instituições que a compõem, para todos os estados brasileiros, especialmente dos Institutos Federais de Educação, Ciência e Tecnologia, ampliou o número de vagas, de candidatos e de matriculados nas Instituições da Rede Federal.

Em decorrência, constata-se a alocação, gradativa, de recursos públicos para investimento nas instituições da Rede Federal. Porém, contraditoriamente, criou-se diferentes mecanismos de apropriação privada de recursos públicos na área.

A partir de 2015, o movimento crescente de alocação de recursos é interrompido, com a diminuição de recursos públicos para investimento na Rede Federal, acentuando-se nos anos de 2016 e 2017. Esse movimento pode comprometer o processo de expansão, o que requer, no entanto, estudos e aprofundamento sobre as suas consequências.

As reflexões apresentadas, com base na conjuntura histórica, sobre o contexto da proposição e o processo da materialização das políticas de educação profissional e tecnológica, reconhecem, apesar de seus efeitos contraditórios, a importância da inserção da sociedade civil no debate e de concepções contra hegemônicas, na definição de políticas educacionais voltadas às demandas sociais e à garantia do direito à educação profissional e tecnológica aos cidadãos brasileiros.

AGRADECIMENTOS: Conselho Nacional de Desenvolvimento Científico e Tecnológico $(\mathrm{CNPq})$.

\section{REFERÊNCIAS}

BANCO CENTRAL DO BRASIL. Calculadora do Cidadão. Brasília, 2019. Disponível em: https://www.bcb.gov.br/acessoinformacao/calculadoradocidadao. Acesso em: 10 abr. 2019.

BRASIL. Ministério da Educação. Educação Profissional 'Concepções. Experiências.

Problemas e Propostas'. Brasília-DF, 2003. Disponível em:

http://www.dominiopublico.gov.br/pesquisa/DetalheObraForm.do?select_action=\&co_obra=2 7112. Acesso em: 31 maio 2018. 
BRASIL. Ministério da Educação. Proposta em discussão: Políticas Públicas para a Educação Profissional e Tecnológica. Brasília-DF, 2004. Disponível em: http://portal.mec.gov.br/setec/arquivos/pdf/p_publicas.pdf. Acesso em 31 maio 2018. BRASIL. Ministério da Educação. Plano de Expansão da Rede Federal de Educação Tecnológica. Brasília: MEC, 2005. Disponível em: http://portal.mec.gov.br/setec. Acesso em: 16 maio 2018.

BRASIL. Lei $\mathbf{n}^{\mathbf{0}}$ 11.892, de 29 de dezembro de 2008. Institui a Rede Federal de Educação Profissional, Científica e Tecnológica, cria os Institutos Federais de Educação, Ciência e Tecnologia, e dá outras providências. Brasília, DF, dez. 2008. Disponível em: http://www.planalto.gov.br/ccivil_03/_ato2007-2010/2008/lei/111892.htm. Acesso em: 12 out. 2018.

BRASIL. Ministério da Educação. Secretaria de Educação Profissional e Tecnológica. Expansão da Rede Federal. Relatório anual de análise dos indicadores de gestão das instituições federais de educação profissional, científica e tecnológica: Exercício 2008. Brasília-DF, 2009. Disponível em:

http://portal.mec.gov.br/index.php?option=com_docman\&task=doc_download\&gid=17981\&I temid= Acesso em: 31 maio 2018.

BRASIL. Ministério da Educação. Secretaria de Educação Profissional e Tecnológica. Expansão da Rede Federal. Relatório anual de análise dos indicadores de gestão das instituições federais de educação profissional, científica e tecnológica: Exercício 2009 e 2010. Brasília-DF, 2011a. Disponível em:

http://portal.mec.gov.br/index.php?option=com_docman\&task=doc_download\&gid=17982\&I temid= Acesso em: 31 maio 2018.

BRASIL. Decreto no 7.589, de 26 de outubro de 2011. Institui a Rede e-Tec Brasil. Brasília, DF, 2011b. Disponível em: http://www.planalto.gov.br/ccivil_03/_ato20112014/2011/decreto/d7589.htm. Acesso em: 12 out. 2018.

BRASIL. Ministério da Educação. Secretaria de Educação Profissional e Tecnológica. Expansão da Rede Federal. Relatório anual de análise dos indicadores de gestão das instituições federais de educação profissional, científica e tecnológica: Exercício 2011. Brasília-DF, 2012a. Disponível em:

http://portal.mec.gov.br/index.php?option=com_docman\&task=doc_download\&gid=17983\&I temid= Acesso em: 31 maio 2018.

BRASIL. Ministério da Educação. Secretaria de Educação Profissional e Tecnológica. Instituto Federal de Educação, Ciência e Tecnologia de Rondônia. Relatório de Gestão do Exercício: 2011. Porto Velho-RO, 2012b. Disponível em:

http://portal.mec.gov.br/index.php?option=com_docman\&task=doc_download\&gid=10635\&I temid= Acesso em: 31 maio 2018.

BRASIL. Lei no 12.677, de 25 de junho de 2012. Dispõe sobre a criação de cargos efetivos, cargos de direção e funções gratificadas no âmbito do Ministério da Educação, destinados às instituições federais de ensino; e dá outras providências. Brasília, DF, jul. 2012c. Disponível em: http://www.planalto.gov.br/ccivil_03/_ato2011-2014/2012/lei/L12677.htm. Acesso em: 12 out. 2018. 
BRASIL. Ministério da Educação. Secretaria de Educação Profissional e Tecnológica. Expansão da Rede Federal. Relatório anual de análise dos indicadores de gestão das instituições federais de educação profissional, científica e tecnológica: Exercício 2012. Brasília-DF, 2013a. Disponível em:

http://portal.mec.gov.br/index.php?option=com_docman\&task=doc_download\&gid=17984\&I temid=. Acesso em: 31 maio 2018.

BRASIL. Ministério da Educação. Secretaria de Educação Profissional e Tecnológica. Instituto Federal de Educação, Ciência e Tecnologia de Rondônia. Relatório de Gestão do Exercício: 2012. Porto Velho-RO, 2013b. Disponível em:

http://portal.mec.gov.br/index.php?option=com_docman\&task=doc_download\&gid=14259\&I temid=. Acesso em: 31 maio 2018.

BRASIL. Ministério da Educação. Secretaria de Educação Profissional e Tecnológica. Expansão da Rede Federal. Relatório anual de análise dos indicadores de gestão das instituições federais de educação profissional, científica e tecnológica: Exercício 2013. Brasília-DF, 2014a. Disponível em:

http://portal.mec.gov.br/index.php?option=com_docman\&task=doc_download\&gid=17985\&I temid= Acesso em: 31 maio 2018.

BRASIL. Ministério da Educação. Secretaria de Educação Profissional e Tecnológica. Instituto Federal de Educação, Ciência e Tecnologia de Rondônia. Relatório de Gestão do Exercício: 2013. Porto Velho-RO, 2014b. Disponível em:

http://portal.mec.gov.br/index.php?option=com_docman\&task=doc_download\&gid=15996\&I temid= Acesso em: 31 maio 2018.

BRASIL. Ministério da Educação. Secretaria de Educação Profissional e Tecnológica. Expansão da Rede Federal. Relatório anual de análise dos indicadores de gestão das instituições federais de educação profissional, científica e tecnológica: Exercício 2014. Brasília-DF, 2015. Disponível em:

http://portal.mec.gov.br/index.php?option=com_docman\&task=doc_download\&gid=17929\&I temid= Acesso em: 31 maio 2018.

BRASIL. Ministério da Educação. Secretaria de Educação Profissional e Tecnológica. Expansão da Rede Federal. Relatório anual de análise dos indicadores de gestão das instituições federais de educação profissional, científica e tecnológica: Exercício 2015. Brasília-DF, 2016. Disponível em:

http://portal.mec.gov.br/index.php?option=com_docman\&view=download\&alias=45621setec-analise-de-indicadores-2015-pdf\&category_slug=julho-2016-pdf\&Itemid=30192 Acesso em: 31 maio 2018.

BRASIL. Ministério da Educação. Secretaria de Educação Profissional e Tecnológica. Expansão da Rede Federal. Relatório anual de análise dos indicadores de gestão das instituições federais de educação profissional, científica e tecnológica: Exercício 2016. Brasília-DF, 2017. Disponível em:

http://portal.mec.gov.br/index.php?option=com_docman\&view=download\&alias=77151relatorio-indicadores-da-rede-federal-2016-pdf\&category_slug=novembro-2017pdf\&Itemid=30192. Acesso em 31 maio 2018. 
BRASIL. Ministério da Educação. Secretaria de Educação Profissional e Tecnológica. Expansão da Rede Federal. Relatório anual de análise dos indicadores de gestão das instituições federais de educação profissional, científica e tecnológica: Exercício 2017. Brasília-DF, 2018. Disponível em:

http://portal.mec.gov.br/index.php?option=com_docman\&view=download\&alias=96381relatorio-anual-analise-dados-indicadores-gestao-2017\&category_slug=setembro-2018pdf\&Itemid=30192. Acesso em: 31 maio 2018.

CIAVATTA, Maria. Formação Integrada: entre a cultura da escola e a cultura do trabalho. In: CIAVATTA, Maria (coord). Memória e temporalidades do trabalho e da educação. Rio de Janeiro: Faperj, 2007.

DOURADO, Luiz Fernandes. Avaliação do plano nacional de educação 2001-2009: questões estruturais e conjunturais de uma política. Educação \& Sociedade, Campinas, v. 31, n. 112, p. 677-705, jul./set. 2010.

DOURADO, Luiz Fernandes. Plano Nacional de Educação: o epicentro das políticas de estado para a educação brasileira. Goiânia: Ed. Imprensa Universitária; ANPAE, 2017.

DOURADO, Luiz Fernandes; ARAUJO, Walisson. Do FNE ao FNPE: a Conape como resistência. Revista Retratos da Escola, Brasília, v. 12, n. 23, p. 207-226, jul./out. 2018. Disponível em: http://retratosdaescola.emnuvens.com.br/rde/article/view/861/pdf. Acesso em: 3 abr. 2019.

FRIGOTTO, Gaudêncio. Os circuitos da história e o balanço da educação no Brasil na primeira década do século XXI. Revista Brasileira de Educação, v. 16, n. 46, p. 235-254, jan./abr. 2011.

GRAMSCI, Antonio. Maquiavel, a Política e o Estado Moderno. Tradução de Luiz Mário Gazzaneo, 5. ed., Rio de Janeiro: Civilização Brasileira, 1984.

INSTITUTO FEDERAL DE EDUCAÇÃO, CIÊNCIA E TECNOLOGIA DE RONDÔNIA (IFRO). Relatório de Gestão: 2015. Porto Velho-RO, 2016. Disponível em: https://portal.ifro.edu.br/doc-isntitucionais/relatorio-de-gestao-1/597-relatorio-de-gestao-de2015-ifro-submissa-o-1/file. Acesso em: 31 ago. 2018.

INSTITUTO FEDERAL DE EDUCAÇÃO, CIÊNCIA E TECNOLOGIA DE RONDÔNIA (IFRO). Relatório de Gestão: 2016. Porto Velho-RO, 2017. Disponível em: https://portal.ifro.edu.br/images/Pro-reitorias/Prodin/Relatórios_de_Gestão_/RG_2016.pdf. Acesso em: 31 ago. 2018.

KUENZER, Acácia Zeneida. Ensino de segundo grau: o trabalho como princípio educativo. 3. ed., São Paulo: Cortez, 1997. 


\section{Como referenciar este artigo}

CONDE, F. M.; OLIVEIRA, R. T. C. Políticas para a educação profissional e tecnológica no Brasil (2003 - 2017). Revista Ibero-Americana de Estudos em Educação, Araraquara, v. 14, n. esp. 3, p. 1797-1812, out., 2019. E-ISSN: 1982-5587. DOI: 10.21723/riaee.v14iesp.3.12764

Submetido em: 25/03/2019

Revisões requeridas: 20/04/2019

Aceito em: 15/05/2019

Publicado em: 30/08/2019 